\title{
On Feasibility of Teacher Training Based on Moodle Platform
}

\author{
Du Juan \\ ZaoZhuang University \\ ShanDong, China
}

\begin{abstract}
As the new curriculum reform raises the higher demands to teachers, many regions have adopted centralized training for teachers in order to improve teachers' awareness of the new curriculum reform. However, due to the limited time and numerous contents, the effect of teacher training is not good. In this context, this study took the training of primary and secondary school teachers as the research object and studied the teaching design of teacher training based on the Moodle (Modular Object-Oriented Dynamic Learning Environment) platform. It was intended to reflect the advantages of the Moodle platform in teacher training, and contribute to development of teacher training.
\end{abstract}

Keywords—Moodle platform; teacher training; teaching design

\section{INTRODUCTION}

With the development of society, science and technology, education has become more and more important in the economic society and people pay more attention to education. The education itself also needs more talents. In this context, China has launched the new curriculum reform. However, teacher education was not as highly regarded as the student education. The imbalance between the progressive educational technology and the backward teaching ability has become a major problem in the education sector today. Therefore, strengthening the construction of the teaching staff, improving the overall quality of the teaching staff, and building a team of energetic and innovative teachers is the top priority of education development.

Comrade Deng Xiaoping has stressed that to achieve socialist modernization, science and technology is the key, and education is the foundation. As primary and secondary school teachers are conducting basic education, the overall quality of primary and secondary school teachers determines the quality of the entire basic education, and also indicates the future core competitiveness of a country. The strategy of rejuvenating the country through science and education was proposed in the 15th National Congress of the Communist Party of China. In 1998, the Ministry of Education formulated the Plan for Education Revitalization for the 21st Century. In 2003, it promulgated the 2003-2007 Education Revitalization Plan which shifted the key tasks of the training of primary and secondary school teachers in China from academic education to continuing education. It is undeniable that the teacher training has scored impressive achievements as the training of the country's teachers has been strengthened. Teachers at all levels and institutions have made a great improvement in terms of ideological and political quality, professional ethics, working performance, and teaching ability. In order to better apply the concepts and methods of the new curriculum reform to practical teaching, there is an urgent need for a comprehensive training for all teachers. Therefore, the use of the network teaching platform to carry out the teaching case study of teacher training, and the analysis and design of the teaching content, are of great significance to the future teacher training work in various regions.

On the basis of the functions and advantages of Moodle network teaching platform, and the characteristics and needs of teacher training, the teaching process of Moodle network teaching platform was designed. Organized training for primary and middle school teachers in the city. It was proved by practice that the teaching design can present the teaching content to the maximum extent, embody the people-oriented education concept, and promote the teachers' teaching ability. After the training, questionnaires were distributed to explore the feasibility of promotion of teacher training methods based on the Moodle platform.

\section{BRIEF INTRODUCTION OF MOODLE}

Moodle platform has simple and exquisite interface and compatibility. It is rich in modular design and easy to operate. It contains management function and network teaching function.

\section{A. Management}

As for the management features, the platform integrates website function which is easy to use. It also features in diversified platform style and complete management tools. On the Moodle platform, what you see is what you get, which reduces the difficulty of use. Users can edit the content on the platform at any time, which is convenient and quick to operate. Moreover, it provides dynamic module management, which means that administrators can install or uninstall modules as needed, or design new modules to redevelop the platform themselves. At the same time, the administrator can give different users the corresponding permissions, making the Moodle platform more flexible and diverse. The Moodle platform also offers a variety of styles for users to choose. Users can also design according to their own preferences. Moodle platform has relatively complete management and maintenance tools, such as log that can look for the usage record of the platform, and backup tool for automatically backing up the data in the platform. 


\section{B. Network teaching}

As for network teaching, Moodle platform supports various types of courses, features in flexible curriculum management, and can track and analyze learning. It has strong grouping functions with multiple evaluation methods, and possesses question bank and a wealth of online teaching modules. The Moodle platform supports three main types of online courses: autonomous, leading, and discussion. Users can freely create courses catalog on the Moodle platform, and course administrators can make adjustments to the course at any time. Each course can be set up with relatively flexible access rights, and course administrators can set courses for certain groups. The Moodle platform tracks learners' learning records and the course administrator can view the learner's learning reports and the number of times the learner has accessed the course, as well as the participation of learners in each module. The reports can be vivid charts that make it easy for course administrators to learn about learners throughout the course. Course administrators can classify learners in sub-classes and sub-groups with the grouping tool on the platform. The Moodle platform provides a variety of evaluation methods so that the learner's learning outcomes can be evaluated by the course administrator and by other learners. This kind of evaluation method can improve the participation of learners, make them reflect on themselves, and greatly improve the efficiency of learning. The Moodle platform has a large online testing system, and course managers can set independent question banks for each course. At present, the platform supports online test questions such as selection, judgment, and blank filling. Both questions and answers can be sorted out-of-order, and test time can be limited. The online teaching modules supported by the platform include discussion, notes, chat, vocabulary, exercises, surveys, training, topics, etc. Course managers have the flexibility to use these modules for teaching.

\section{Unique advantages:}

\section{1) Flexible learning time}

Unlike the traditional teaching, the Moodle platform gives us a broader choice, and we can participate in any time we want to learn, free of the limitation of time and locations.

\section{2) Diverse communication methods}

In the Moodle platform, learners can choose blogs, chats, or other ways to communicate with teachers. When they have puzzles, they can get help from teachers immediately.

\section{3) Rich learning materials}

The Moodle platform provides channels for uploading a variety of materials. Learners can read articles, watch videos, images and browse other resources to better understand what they have learned.

\section{4) Teaching for different levels}

Teachers can use the platform to know the level of learners and provide corresponding help for different learners.

\section{ANALYSIS OF TEACHER TRAINING FEASIBILITY BASED ON MOODLE PLATFORM}

This study took the trained teachers and trainers in the primary and middle school teacher training organized by Zaozhuang Normal School in Zaozhuang City, Shandong
Province as the research object, and took the form of issuing questionnaires to explore comprehensively the feasibility of teacher training based on the Moodle platform.

Through carefully design and analysis of the questionnaire, it understood the current situation of the teacher, including the age, title, education, the information technology conditions and level of the teacher's environment, the understanding and use of the Moodle platform, the evaluation of the use of the Moodle platform, etc. Moreover, it analyzed the advantages and weaknesses of teacher training based on the Moodle platform, providing a reference for teachers' teaching in the future.

\section{A. Design and issue questionnaires}

The questionnaire should be compiled with consideration of the questionnaire dimension, the type of questions and the topics and options involved. Revise the questions according to the reliability and validity of the questionnaire. Finally the formal questionnaire can be issued to the respondents.

\section{1) Design interview outline}

According to the research objectives, the interview centers on the following aspects. 1. Teacher attendance and information technology level of trained teachers. 2. How do trainers use Moodle platform. 3. How do trained teachers use Moodle platform. 4. The use of Moodle platform for teaching design. 5. Trainer's evaluation of the platform's instructional design. 6. Trainer's recommendations for the use of the platform.

\section{2) Questionnaire}

Combined with the interview, the questionnaire was set into four dimensions. 1. Teacher's personal information. 2. Information technology conditions and level. 3. The understanding and use of Moodle platform. 4. Evaluation of the use of the Moodle platform. A total of 20 questions were designed, including 13 single-choice questions, 5 multiple-choice questions, and 2 essay questions. The "teacher personal information” covers choice questions 1-6; "information technology conditions and levels" corresponds to questions 7-11; "the understanding and use of Moodle platform" are involved in questions 12-16; "Evaluation of the use of the Moodle platform” covers questions 17-20. Among them, the 15th to the 18th questions include several sub-questions for detailed research. For details, please refer to Appendix 2: Questionnaire on the Use of Moodle Platform in Teacher Training in Primary and Secondary Schools.

\section{3) Issue questionnaire}

Issue the questionnaire after being revised and improved.

The questionnaire was distributed to 233 teachers who participated in the training of primary and secondary schools in Zaozhuang City, Shandong Province from 2008 to 2010. 233 questionnaires were distributed with 228 collected. The number of valid questionnaire was 223 . The retrieving rate was $97.9 \%$ and the valid rate was $95.7 \%$.

\section{B. Survey results}

1) Basic information of trained teachers

It can be seen from the results of the questionnaire that the male teachers are in majority as male-female ratio of trained 
teachers is 67.5:32.5. They are aging from 31 to 40 , mostly teaching science and engineering professions. The proportion of the teachers with three-level profession title is the highest $62.7 \%$. The second-level teachers account for $35.1 \%$. Only $2.2 \%$ are first-class teachers, and there are no senior teachers. Most trained teachers' schools are located in rural areas.

\section{2) Information technology conditions and levels}

According to the results of the questionnaire, homes and schools are the places where the trained teachers use the computers most frequently. These environments are suitable for studying with the Moodle platform. Apart from class hour, a majority of teachers often use computers after class. Therefore, when designing courses based on Moodle platform, we should give full play to the advantages of the platform and utilize various resources to ensure that every teacher who enters the platform can gain. Most teachers can use Word proficiently, and often use PowerPoint and Excel. But only a handful of teachers know something about of PhotoShop and FLASH. This provides a favorable precondition for using the Moodle platform, but poses challenges for the in-depth study of the course. Before training, the trained teachers mostly use computer to listen to music and chat, and only $12.06 \%$ of teachers use computers to prepare lessons. Therefore, in the teaching design based on Moodle platform, we should pay attention to cultivate habits of trained teachers to use computers to prepare lessons. The main way for trained teachers to solve information technology problems before training are to ask information technology teachers (33.7\%) and discuss with colleagues (31.3\%). Only $15.5 \%$ of them searched online. It can be seen that teachers are not accustomed to using the network to solve problems. Therefore, in teaching design based on the Moodle platform, we should cultivate their habit of using the network to solve problems.

\section{3) Understanding and usage of the Moodle platform}

From the questionnaire results, it can be concluded that remarkable changes have took place in the information technology habits of the trainees after training. The teachers spend more time working on computer the time; the number of trained teachers using computers to prepare for classes has increased significantly, and the number of people watching movies and playing games has dropped significantly. All these indicate that teachers are gradually form the habit of preparing lessons with computers. What's more, the good habit of using the network to solve problems is being developed as the frequency of online search has been significantly improved.

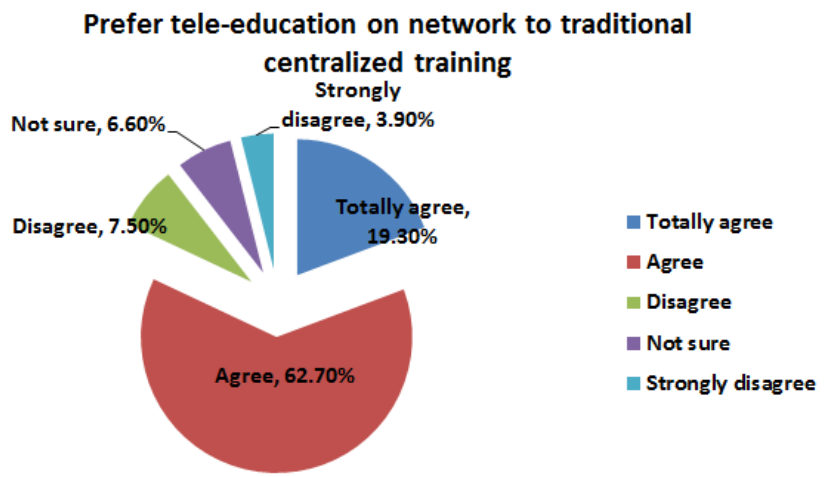

Fig. 1. Prefer tele-education on network to traditional centralized training.

\section{Summary}

The following conclusions are drawn from the questionnaire survey:

(1) The trained teachers believe that the platform design is intuitive and concise with a large amount of information, modules, and multiple applications. Using the Moodle platform can help them learn knowledge and skills, which can effectively improve the teaching effect.

(2) The trained teachers have not accessed the Moodle platform before the training, and the trainers have not been working with the Moodle platform long enough. Therefore the promotion of the Moodle platform needs to be strengthened.

(3) The instructional design based on the Moodle platform can greatly help the trained teachers in the following work. However, in the teacher training, the Moodle platform is mainly used to present resources which are mainly teaching plans and courseware. The teachers' favorite interactive evaluation modules and resource modules are not frequently applied. So the use of these two modules should be emphasized in the instructional design. At the same time, the teaching design should pay attention to the communication between the trainer and the trained teacher on the Moodle platform.

(4) Platform teaching changed the original teaching ideas of the trained teachers and they began to try to collect materials and online courses from the Internet. However, there are still some problems in the use of the Moodle platform. For example, the knowledge points are not layered, and the grouping function and the survey module need to be further improved. The requirements for hardware are relatively high, and special personnel are needed for hardware maintenance.

(5) The Moodle platform can be popularized.

\section{CONCLUSION}

Although the Moodle platform has been launched for a long time, it has not been popularized in China. So we need experts and scholars to promote it, and facilitate more people to understand and use the Moodle platform. This is one of the purposes of this research. I hope that in the near future, everyone can learn and make progresses on the Moodle platform.

This paper explored the feasibility of using the Moodle platform to support teaching design of teacher training based on theoretical research, questionnaires and interviews. By issuing questionnaires to teachers who have already received training, it analyzed the feasibility of teacher training based on Moodle platform, which provides a reference for the teaching design of teacher training using Moodle platform. However, due to the inadequate study time and the limitations of capabilities, there are still many shortcomings in the research. For example, the interactive evaluation module and test module that attract trained teachers are not further studied. So there is still a lack of analysis on the evaluation of emotional attitudes and values.

\section{REFERENCES}

[1] Ma Chizhu, Wang Hong, Qin Lu. Experimental Verification and Evaluation of Peasant Distance Training Mode Based on Moodle 
Platform [J].China Educational Technology, 2016(03):50-56.,In Chinese.

[2] Wang Guangming, Zhang Nan, Kang Yueyuan. On Educational Software Training Content from the Perspective of Mathematics Teacher Training [J]. Theory and Practice of Education, 2015, 35(35):35-37. ,In Chinese.

[3] Wang Ying, Wang Qiong. Design and Practice of Double-Loop Learning Based on Moodl - Taking the Training of Interactive Whiteboard Network of Primary and Secondary School Teachers in China as an Example [J].China Educational Technology, 2015(11):84-90. , In Chinese.
[4] Liu Xuan, Wang Baohua. On the collaborative training mode of "National Training Program" under the Moodle platform [J]. Education and Vocation, 2011(29): 190-191. ,In Chinese.

[5] Zhang Jiahua, Zou Qin, Zhu Zhiting. Online Learning Depth Analysis Based on Moodle Platform [J].E-education Research, 2016, 37(12):46-51. ,In Chinese.

[6] Shen Liangzhong, Zan Xiangzhen, Gao Manru. Teacher-student learning community construction based on Moodle platform [J]. Theory and Practice of Education, 2018, 38(03):40-41. , In Chinese. 